\title{
Las minorías lingüísticas y culturales en Italia: el caso de la lengua y de la cultura arbëreshë
}

\author{
Giuliano Tardivo, Eduardo Díaz Cano \\ UNIVERSIDAD REY JUAN CARLOS, MADRID, ESPAÑA \\ giuliano.tardivo@urjc.es, eduardo.diaz@urjc.es
}

\begin{abstract}
Resumen: Este texto presenta los resultados de una investigación sobre la población y cultura arbëreshë, asentada en el sur de Italia desde el siglo XV y provenientes de la antigua Albania. La metodología de estudio es una triangulación entre la documentación existente, la observación participante, una encuesta y varias entrevistas en profundidad realizadas a directores de museos etnográficos y determinados miembros de la comunidad arbëreshë residentes en los pueblos San Costantino Albanese y Civita, algunos de los más importantes de la Italia arbëreshë. Los resultados demuestran que se trata de una minoría bien integrada en la cultura receptora, que a pesar del tiempo transcurrido desde su llegada y las pocas incorporaciones, la cultura originaria sigue presente especialmente a través de su idioma y, si bien entre los jóvenes el arbëreshë empiece a ser menos utilizado, sigue cumpliendo cierta función social.
\end{abstract}

Palabras Clave: minorías lingüísticas, arbëreshë, Skanderbeg, tradiciones, discriminaciones

Abstract: This paper presents the results of a research carried out to study the Arbëreshë culture and population, who coming from the old Albania, reside since the 15th century in the southern Italy. The methodology used in this work has different levels: First to analyze the academic papers, which have also helped to define what their culture is and where it is spread, second, the participant observation, and third, a questionnaire and in-depth interviews with directors of ethnographic museums and Arbëreshë people of the villages of San Costantino Albanese and Civita, some of the most important in the Arbëreshë Italy. The results show that it is a well-integrated minority in the host culture, that even though it is a long time since the first Arbëreshë arrived to Italy and not so many arrived in the following centuries, their culture continues alive specially through its language, which begins to be less used among young people, but it continues fulfilling a certain social function.

Keywords: linguistic minorities, Arbëreshë, Skanderbeg, traditions, discriminations

\section{Introducción}

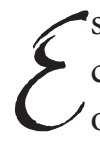
ste artículo se divide en cinco apartados: en el primero haremos una introducción histórica sobre la población arbëreshë; en el segundo describiremos los objetivos, el marco teórico y la justificación de nuestro trabajo; en el tercero profundizaremos sobre la metodología utilizada para llevar a cabo nuestra investigación; en el cuarto apartado presentaremos los principales resultados y, por último, en el quinto, las principales conclusiones.
} 
Antes de entrar más directamente en nuestro trabajo, se hace necesaria, a nuestro juicio, una introducción histórica sobre la población arbëreshë, porque se trata de una población por lo general poco conocida y tomada en consideración por la literatura científica italiana e internacional.

Según Letizia Miraglia (2000) la población arbëreshë global ronda las 200.000 personas, residiendo hoy en día en Italia un número cercano a las 100.000 personas (Cole, 2011:15; Bloise, 2013:231; Ethnologue, 2016 y Altimari, 1994: 21) por lo que es de gran importancia el analizar su situación actual. Las cifras manejadas podrían variar pues el censo italiano no tiene en cuenta estas consideraciones de origen o cultura minoritaria en su recogida de datos. Por otra parte, las denominaciones para este grupo de personas son varias: arbëreshë, minoría italo-albanesa o arbería (Sanmartí Roset, 1995: 247) y para su idioma «albanés, arberesco o arvanita» (Sanmartí Roset, 1995: 538), aunque mantendremos la denominación arbëreshë en todo el texto.

Las comunidades arbëreshë se encuentran diseminadas, principalmente, por todo el sur de Italia: Sicilia, Apulia, Molise, Basilicata, Calabria. Como consecuencia de la emigración existen comunidades arbëreshë incluso en el Norte de Italia, por ejemplo en Turín (Tagarelli, 2004), en EE.UU (Jurgens, 2017), Argentina y Brasil (Bruni, 2004). Todavía hoy se encuentran en EE.UU. arbëreshë de tercera generación que dominan y utilizan habitualmente la lengua arbëreshë (Tagarelli, 2004: 31).

Aunque la historia de Calabria y de Basilicata durante la Edad Media carece de fuentes originales fiables (Cozzetto, 2013: 17-18), basándonos en estudios recientes, podemos afirmar que los primeros centros albaneses permanentes se crearon en el sur de Italia en el siglo XV, sobre todo después de 1468 (Altimari, 1994: 9; Amato, 2016: 24; Pieroni et al., 2002: 219), por albaneses del centro-sur de su país que huyeron de su tierra después de la invasión otomana. Entre 1468 y 1506 (Amato, 2016: 28) surgieron algunas comunidades arbëreshë como la de Frascineto y la de Civita. Los primeros asentamientos estables de albaneses en Calabria se constituyeron realmente sólo a finales del siglo XVI (Serpe, 2012: 18). Los arbëreshë del norte de Calabria eran cristianos de la Iglesia Ortodoxa, pero con el paso del tiempo en muchos pueblos arbëreshë se creó una situación de hibridismo o mestizaje, una especie de mezcla de tradiciones latina y bizantina (Miraglia, 2000: 321). Esto se hace evidente, por ejemplo, en la Iglesia de San Costantino, que tiene tres naves, como las iglesias latinas, pero en su interior no hay cuadros sino iconos. El cura se puede casar y celebra la misa dando la espalda a los fieles.

En 1508 se habían asentado en Calabria por lo menos unos 40 pueblos albaneses (Cozzetto, 2013: 19). En el pueblo de Civita, que hemos visitado durante la recogida de los datos, la presencia albanesa data de 1487 (Dalena y Di Muro, 2013: 43). En zonas de la Calabria central los albaneses en el siglo XVI permitieron repoblar terri- 
torios que habían quedado despoblados por terremotos y la Peste (Filippelli, 2011: 10; Morassi, 1989:176; Sánchez-David, 2008: 133). Según el mito popular, un papel fundamental en la creación y consolidación de los pueblos arbëreshë y de la presencia albanesa lo ejerció Giorgio Castriota Skanderbeg (Dalena y Di Muro, 2013: 36-37; Artemel, 1965). Skanderbeg luchó al servicio de los aragoneses, Alfonso V (Servantie, 2003: 80; ), y en contra de la Casa de los Anjou (Montobbio, 2009; Marinescu, 1923) recibiendo a cambio tierras en la zona de Catanzaro (Cole, 2011:15), aunque resulta complicado distinguir entre mito e historia en relación a este personaje, y algunos historiadores ponen en duda la autenticidad de estos acontecimientos «mitológicos» (Dalena y Di Muro, 2013: 42), pero otros corroboran la parte histórica (Schmitt, 2009; Elsie, 2010:401). A pesar de esas dudas sobre su real existencia, la figura de Skanderbeg sigue ejerciendo mucha influencia en la cultura arbëreshë y sigue celebrándose durante la Semana Santa (Amato, 2016: 10). Los albaneses llegaron a Italia con una tradición sólo oral, por eso la cultura arbëreshë escrita se ha expresado casi exclusivamente en italiano (Miraglia, 2000: 312). El primer documento escrito que podríamos considerar como propio de la literatura arbëreshë lo encontramos a finales del siglo XVI, y es obra de Luca Matranga (Altimari, 1994: 13), pero sólo a mitad del siglo XVIII, con Giulio Variboba, «la literatura arbëreshë da un verdadero paso adelante» (Altimari, 1994: 14). En el siglo XIX la literatura arbëreshë comienza su desarrollo. En 1848 nació el primer periódico arbëreshë, L’albanese d'Italia (reeditada por Rubbettino una compilación de los primeros 28 números en junio de 2017 y presentada por Altimari). A pesar de estos intentos y esfuerzos, individuales y grupales, la cultura arbëreshë sigue siendo una cultura sobre todo oral (Altimari, 1994: 23), lo cual, como recuerda Tullio De Mauro, aumenta el riesgo de que un idioma sea «arrasado por el devenir histórico-social» (Ragni, 2007: 2). Se trataba, además, de un pueblo nómada, formado en gran parte por pastores. En 1835, por ejemplo, en San Paolo Albanese vivió un obispo que se hizo pasar por cura católico (Miraglia, 2000: 314). «La lucha por la defensa bizantino del rito griego-bizantino -dice Altimari- no tuvo sólo un carácter religioso, representó un momento de resistencia a la asimilación que procedía del poder y de los grupos dominantes» (Serpe, 2012: 31). Curiosamente, muchos italo-albaneses fueron protagonistas del «Risorgimento Italiano» en el siglo XIX (Cozzetto, 2013: 19; Scutari, 2010; Rizzo y Stella, 2010). A pesar de la importancia histórica de la presencia albanesa en Italia, sólo después de la II Guerra Mundial se difundieron estudios antropológicos en Italia que analizaron y profundizaron (Miraglia, 2000: 329) sobre la cultura arbëreshë. Además, en los años posteriores a la Segunda Guerra Mundial muchas iglesias de esta zona de Basilicata y Calabria del Norte recuperaron elementos bizantinos y lo mismo ocurre con elementos del rito religioso. 


\section{Objetivos, marco teórico y justificación}

Nosotros, por razones de oportunidad, nos hemos centrado sólo en los arbëreshë que viven alrededor del confín entre las regiones de Basilicata y Calabria, en las zonas del Parco Nazionale del Pollino. En Basilicata hay cinco pueblos arbëreshë, todos situados en la provincia de Potenza, mientras que en el norte de Calabria, en la provincia de Cosenza, hay unos 25 pueblos arbëreshë. Otra característica peculiar de los arbëreshë de esta zona, que les diferencia de otras comunidades arbëreshë, es el hecho de que los que se quedaron a vivir en el norte de Calabria, y en San Costantino y San Paolo Albanese (Basilicata), que son los que hemos tomado en consideración para nuestra investigación, eran grecánicos, (Sacco, 2007: 214) es decir cristianos de la Iglesia Ortodoxa y procedían de una zona del Peloponeso que por aquel entonces era parte de Albania y que hoy es territorio griego. Nosotros hemos tomado en consideración, para llevar a cabo nuestra investigación, los pueblos más aislados del Pollino (Calabria del Norte y Basilicata), -San Costantino Albanese, San Paolo Albanese, Frascineto y Civita- para averiguar si y cómo se siguen utilizando tanto la lengua como la cultura arbëreshë. La principal pregunta de investigación que hemos formulado y que nos ha servido como guía durante el proceso de recogida de los datos es la siguiente: ¿Se siguen utilizando la lengua y la cultura arbëreshë y cuáles son las razones, teniendo en cuenta que han pasado más de cinco siglos de la llegada de estas comunidades a Italia del sur? Además, de las siguientes preguntas: ¿Qué función social ha tenido y sigue teniendo este idioma? ¿En qué contextos se habla más: en familia, en conversaciones con amigos, en el trabajo, o con fines políticos e identitarios? Edad, profesión y clase social son las variables que hemos tomado en consideración para comprobar si de alguna forma influyen sobre el uso del arbëreshë. Por último, nos hemos preguntado: ¿así como ocurre con otras minorías lingüísticas y culturales, también los que pertenecen a la cultura arbëreshë sufren discriminaciones o perciben como un problema la pertenencia a esta minoría lingüística y cultural y llegan a avergonzarse por la misma?

A continuación vamos a resumir los dos principales objetivos de este artículo:

1. Analizar los resultados de nuestro trabajo de campo y de los cuestionarios y comprobar si se siguen utilizando tanto la lengua como la cultura arbëreshë en los pueblos que hemos tomado en consideración para nuestra investigación, qué variables influyen a la hora de hablar arbëreshë y cuál es la función que tiene la lengua arbëreshë en estas comunidades.

2. Verificar el nivel de rechazo percibido a través del sentimiento de vergüenza y comprobar si los arbëreshë viven su cultura, su idioma y su identidad con vergüenza o, al contrario, con orgullo. 
Como marco teórico de referencia hemos tomado en consideración no sólo a los autores del pasado que han reflexionado o llevado a cabo investigaciones sobre los arbëreshë y otras minorías lingüísticas y culturales. A pesar del escaso número de estudios existentes sobre este tema, somos conscientes del hecho que sin una base teórica de referencia el material empírico se convertiría en un mero conjunto de datos sin posibilidad de coherencia ni de interpretación ni de generalización. Por consiguiente, intentamos tener en cuenta también que la tradición, aunque se trata de algo heredado e incorporado, nunca se perpetúa igual a sí misma, ni permanece estática (Bargero, 2016: 2; Pavanello, 2010: 72). Formas de vida y juego del lenguaje, como nos ha enseñado el segundo Wittgenstein (1999:5-9), están muy relacionados (Bargero, 2016: 3). Hemos tomado en consideración también el concepto de habitus de Pierre Bourdieu. Como dice Tylor (1920:1) «Cultura o civilización, tomado en un sentido etnográfico amplio, es aquella totalidad compleja que incluye el conocimiento, las creencias, las artes, la moral, ley, las costumbres y cualquier otra habilidad y hábitos adquiridos por el ser humano como miembro de una determinada sociedad», y, más adelante precisa que «los diferentes grados civilizatorios, cada uno como resultado de su historia previa, es también el presupuesto para dar forma a la historia futura». Es, con estas dos ideas de fondo, con las que realizamos este análisis: la historia, su procedencia para clarificar el origen del presente, y la prospectiva para plantear alguna línea sobre el hacia dónde de esta comunidad heterogénea pero con un origen común aun vivo.

Este texto tiene como referencia teórica, además de la sociología, también el campo de la antropología, de la sociología del lenguaje, de las lenguas y la sociolingüística.

La principal hipótesis que hemos formulado al principio de nuestra investigación se refiere al hecho de que, con mucha probabilidad, tenían que ser las personas más ancianas y menos cosmopolitas las que más utilizaban el arbëreshë (Rizzo y Stella, 2010). Otras hipótesis más específicas que comprobaremos en los apartados dedicados a los resultados y a las conclusiones son: es muy probable que el arbëreshë sea utilizado como segunda lengua, en casa, con familiares y amigos, pero no en el trabajo o en situaciones más formales. Es posible, además, que una parte de los arbëreshë viva con cierto sentimiento de vergüenza su pertenencia cultural.

Por lo que concierne a la justificación del trabajo, queremos estudiar esta cultura y este idioma desde un punto de vista sociológico, además de antropológico (Stocking, 2002). Además es un tipo de cultura poco conocido y estudiado, al menos por los científicos sociales españoles, y tiene importancia histórica, porque las comunidades arbëreshë se constituyeron durante la dominación española. A través de este estudio, pretendemos, por consiguiente, introducir una línea de investigación poco 
desarrollada en España. Por último, hay que tener en cuenta que el idioma está en peligro de desaparición y así lo recoge la Unesco (Salminen, 1999), por lo tanto urge un estudio sobre el estado de salud del idioma y de la cultura arbëreshë.

Imagen 1

En rojo, situación geográfica en Italia de las comunidades arbëreshë

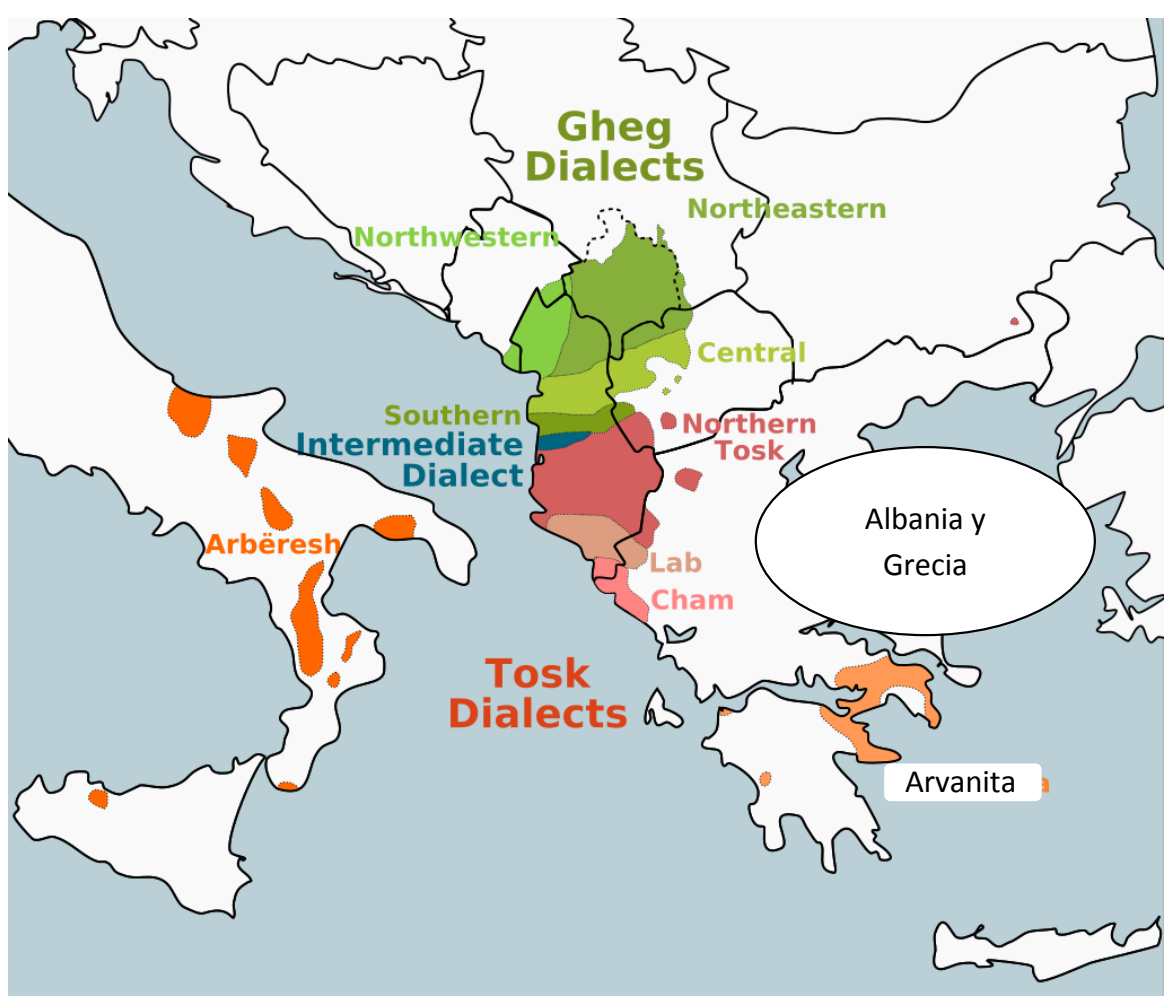

Fuente: Google Maps.

\section{Diseño metodológico}

Para llevar a cabo el presente trabajo hemos utilizado una estrategia triangular entremétodos, porque incrementa «la validez de los resultados» (Álvarez Álvarez y San Fabián Maroto, 2012). La complejidad de los hechos etnográficos puede ser abordada exclusivamente desde una perspectiva plural (Gómez Pellón, 2012). La temática abordada es compleja y necesita a la fuerza para una comprensión profunda y global una perspectiva teórica y metodológica amplia y multidimensional. Hemos 
utilizado un diseño triangular "para equilibrar los sesgos de cada método" (Callejo, 1998: 107). En nuestro caso, ambos tipos de técnicas, cuantitativas y cualitativas, se han utilizado a lo largo del tiempo de forma combinada, «con la intención de que se refuercen ambas» (Callejo, 1998: 115), Utilizando la terminología de Callejo podríamos hablar de un diseño de articulación diacrónica. En especial hemos llevado a cabo una encuesta, a través de un cuestionario que, gracias a la ayuda de algunos intermediarios culturales, hemos repartido a 100 personas residentes en los ayuntamientos de San Costantino Albanese (60) y Civita (40). El cuestionario repartido se componía de siete ítems: los primeros tres se referían al perfil sociodemográfico de los encuestados (edad, profesión y clase social), mientras que los otros cuatro se referían más directamente a la lengua y a la cultura arbëreshë. El último ítem quería averiguar si los encuestados han llegado a avergonzarse en algún momento de su vida por el hecho de ser arbëreshë. Además hemos usado el análisis de documentos -que constituye «un camino indispensable para reconstruir (...) los hechos» (Pavanello, 2010: 27) y un complemento indispensable del trabajo de campo (Stocking, 2002: 33)-, y otras técnicas como la observación participante, o trabajo de campo (Rostagnol, 2011), porque, como decía Franz Boas en 1904, la antropología se tiene que ocupar de «la lingüística aplicada a pueblos sin lenguaje escrito», como en el caso del pueblo arbëreshë. Hemos realizado también unas entrevistas en profundidad con expertos (Uña Juárez y Martín Cabello, 2009: 84), responsables y guías de museos etnográficos de San Paolo Albanese, San Costantino Albanese, Frascineto y Civita, y una entrevista en profundidad con el último sastre que todavía realiza a mano los vestidos típicos arbëreshë. La recogida de los datos se ha llevado a cabo durante los veranos de 2015 y 2016.

\section{Resultados}

A continuación presentamos los principales resultados conseguidos a través de la encuesta y de las otras técnicas utilizadas para recoger nuestros datos.

El 53\% de los encuestados declara hablar perfectamente arbëreshë. Se trata sobre todo de jubilados y en mayor medida de personas que viven en el pueblo de San Costantino. La clase social de pertenencia, sin embargo, parece influir menos que la edad. Casi todos los habitantes de San Costantino encuestados contestan que sí hablan perfectamente arbëreshë. En Civita, sin embargo, sólo una reducida minoría lo habla. A este respecto resulta curioso cómo, en el ámbito de pueblos del profundo sur de Italia, donde todavía los precios de vivienda y comida son asequibles, profesionales como profesores o empleados de la administración pública -es decir, personas que seguramente en un contexto urbano se colocarían en la clase mediase sitúen en la clase alta. 
En Civita menos personas hablan perfectamente arbëreshë y 12 personas de los 40 encuestados declaran que no lo hablan en absoluto. Más rotunda es la respuesta en San Costantino: ninguno lo habla. Uno de los ítems del cuestionario concierne a la función social de la lengua arbëreshë. Hemos llevado a cabo una pregunta multirespuesta que preveía la posibilidad de elegir entre la función de mantener vivas las tradiciones, la de diferenciarse de los demás italianos por razones étnicas y religiosas y, por último, distinguirse de los demás habitantes de la zona que no lo hablan. Resumimos los resultados de este ítem del cuestionario en la tabla que presentamos a continuación:

Tabla 1.

Función de la lengua arbëreshë

\begin{tabular}{l|l|l}
\hline Mantener vivas las tradiciones & $\begin{array}{l}\text { Diferenciarse de los demás italia- } \\
\text { nos, por razones étnicas y religiosas }\end{array}$ & $\begin{array}{l}\text { Diferenciarse de los demás habitan- } \\
\text { tes de la zona que no lo hablan }\end{array}$ \\
$97 \%$ & $1 \%$ & $2 \%$ \\
\hline \hline
\end{tabular}

Fuente: Elaboración propia.

Según lo que hemos podido averiguar con los datos recogidos, tanto cuantitativos como cualitativos, son los más jóvenes de Civita y de Frascineto, dos pueblos situados en el Norte de Calabria, en la provincia de Cosenza, los que menos dominan y utilizan la lengua arbëreshë. San Paolo Albanese, uno de los pueblos visitados, figura como el pueblo que más ha sabido mantener la lengua y las tradiciones, en parte porque es el más pequeño y más aislado geográficamente. «El traje tradicional que se llevaba todos los días, aquí en San Costantino, ya no se lleva desde hace 10 años, cuando murieron las últimas señoras mayores. En San Paolo sí, quedan todavía (...) allí en San Paolo Albanese hay incluso una señora de 60 años, que lo lleva normalmente» (Responsable Museo étnico de San Costantino, mujer de unos 45 años). Se trata de algo que nos ha confirmado también la guía del museo de la cultura arbëreshë de San Paolo Albanese, que nos ha guiado durante nuestra visita al museo: «Aquí todavía quedan 6 o 7 señoras que llevan el traje típico a diario, es el único pueblo de la Basilicata en el que quedan todavía señoras que lo llevan todos los días». Además, «estas señoras cuando mueren son enterradas con estos vestidos». Sin embargo, las chicas más jóvenes, incluso en San Paolo Albanese, «se lo ponen sólo en los días de fiesta, en las bodas» (Guía del museo de la cultura arbëreshë de 
San Paolo Albanese, mujer de unos cincuenta años). De todas formas, quedan muy pocos jóvenes en estos pueblos: "Aquí no hay trabajo y si no hay trabajo aquí no puedes estar, arbëreshë o no arbëreshë da igual» (Guía del museo étnico de Frascineto, mujer de unos 45 años). Un joven de 22 años, con madre arbëreshë y padre de un pueblo de Calabria no arbëreshë, que trabaja como voluntario por un año en el museo étnico de Frascineto, se ha sorprendido cuando le hemos revelado que en San Paolo todavía quedan unas señoras que llevan el traje típico a diario: «¿En serio? ¿Todos los días?», ha sido su sorprendida reacción. La guía del museo de Frascineto nos ha confirmado que «en San Paolo están más cerrados, nosotros aquí tenemos la salida de la autopista (...), viene más gente extranjera, estamos menos aislados». San Paolo Albanese es un pueblo aislado -con unos 150 habitantes reales- sobre todo durante el largo invierno:

Agosto es un mes muy bonito - nos ha dicho la guía del museo de la cultura de San Paolo- pero el invierno es duro, hace frío, no hay tiendas, no hay panaderías, hay una farmacia abierta sólo en ciertos horarios, el médico está presente sólo dos horas al día (...) hay un bar, en invierno hace unos veinte café diarios, esta mañana [una mañana de principios de agosto], la señora del bar la veía cansada porque no está acostumbrada. En Acquaformosa [un pueblo arbëreshë que no hemos visitado para recopilar nuestros datos] pasa lo mismo que en San Paolo, están más aislados y mantienen más las tradiciones.

De hecho en Frascineto no queda ninguna mujer que lleve el traje a diario: «Mi abuela sí lo llevaba, pero hablamos de hace treinta años» (Guía del museo étnico de Frascineto).

En Frascineto sólo los más ancianos, como el sastre de 82 años que hemos entrevistado durante nuestro trabajo de campo, siguen hablando en arbëreshë:

Hemos crecido y nacido aquí, nuestra lengua es el albanés (...). De vez en cuando viene alguien de fuera y me esfuerzo para hablar en italiano (...). El italiano lo aprendí en el colegio, pero es mi segundo idioma (...) Además, aquí en Frascineto ya desde los años cincuenta visten todos 'normal' (Sastre de Frascineto, hombre de 82 años).

Sobre la posibilidad de que el idioma arbëreshë desaparezca en el futuro, el sastre nos ha dicho:

Hasta ahora, durante 500 años, se ha mantenido, en el futuro depende, muchos jóvenes se han tenido que marchar (...) yo soy el único, por lo menos que yo sepa, que queda todavía que sepa coser a mano estos vestidos, porque necesitan horas de trabajo y pueden costar 6 mil euros (Sastre de Frascineto).

Durante nuestra visita a Civita hemos llevado a cabo un trabajo etnográfico, recogido a través de notas de campo y recogida de datos visuales. Cuando el director 
del museo etnográfico de Civita ha querido comentar algo sobre nuestra insistencia para llevar a cabo una entrevista ha empezado a hablar en arbëreshë con otro responsable del museo para que no le entendiéramos. Lo mismo ha ocurrido en San Paolo Albanese, dado que la directora del museo, con la que habíamos hablado por Internet en los días anteriores, estaba ausente el día de nuestra visita. La encargada presente llamó a la directora para averiguar que efectivamente habíamos reservado una visita y habló con ella en la lengua arbëreshë. El cambio repentino de un idioma a otro, llamado switching (Berruto, 2004: 11; Garrido, 2013: 345) tiene un objetivo claro y de comprensión inmediata: se trata de un comportamiento lingüístico frecuente en las zonas de Italia en las que se habla, además del italiano, a la vez otra lengua, y no un simple dialecto. Ocurre, por ejemplo, en zonas del Trentino Alto Adige, con el alemán (Berruto, 2004: 18).

Otra pregunta, que hemos puesto a nuestros encuestados, concierne al contexto en el que se usa más a menudo el arbëreshë. El $82 \%$ de los encuestados declara usarlo en casa, en las conversaciones familiares. El 66\%, con amigos. El 9\%, en el trabajo. Mientras que absolutamente nadie ha elegido la opción: «sólo en los días de fiesta». La guía del museo de la cultura arbëreshë de San Paolo Albanese nos ha confirmado que el uso de la lengua arbëreshë nada tiene que ver con el folclore o el turismo: «es un idioma cotidiano, lo usamos siempre, en casa, con los amigos, en los bares».

Tomamos ahora en consideración la última pregunta del cuestionario, que concierne el sentimiento de vergüenza que podría acompañar el hecho de pertenecer a la cultura arbëreshë. De los 100 encuestados, sólo 8 dicen haberse avergonzado de su cultura: 6 siempre, y dos, sólo en algunas ocasiones.

Tabla 2.

Cultura arbëreshë y sentimiento de vergüenza

\begin{tabular}{l|c}
\hline RESPUESTA & RESULTADO \\
\hline Sí, ME HE AVERGOZADO & $6 \%$ \\
\hline Sí, SÓLO EN ALGUNAS OCASIONES & $2 \%$ \\
\hline NO, NUNCA ME HE AVERGOZADO & $92 \%$ \\
\hline \hline
\end{tabular}

Fuente: elaboración propia

Este dato ha emergido también por medio del trabajo etnográfico y de las entrevistas: «Cuando yo me ponía el traje arbëreshë - nos ha dicho la guía del museo de San Paolo Albanese- tenía un inmenso orgullo, soy orgullosa de decir que soy una alba- 
nesa de Italia». El orgullo es algo que hemos detectado en todas las personas con las que hemos podido hablar: "yo digo siempre a mi novio, que es de Castrovillari [un pueblo de Calabria no arbëreshë] que ojalá todos tuvieran su suerte, de encontrar un arbëreshë como yo, porque somos más serios, respetamos siempre la palabra dada, tenemos una marcha más respecto a los demás» (guía del museo étnico de Frascineto). En este caso, sin embargo, el respeto de las normas arbëreshë se cumple, pero no porque salga rentable cumplirlas (Martínez García, 2017: 2): «Bueno, si vives en Milán y dices que eres albanés, ¡madre de Dios!», nos ha dicho la guía del museo de Frascineto. De hecho, muchos de los que hemos contactado han querido subrayar que se sienten albaneses de Italia, y que no tienen nada que ver, por estilo de vida, concepción de la mujer, etc., con los albaneses que viven en Albania. «En Albania no saben ni comer espaguetis», nos ha revelado, entre risas, la guía del museo étnico de Frascineto.

\section{Discusión de resultados y conclusiones}

Al final de este trabajo, podemos brindar unas respuestas no definitivas pero sí orientadoras a las preguntas y a las hipótesis planteadas en la introducción.

Queda confirmada la hipótesis que relaciona la lengua arbëreshë con las personas más ancianas y que viven en el pueblo más aislado de los que hemos tomado en consideración, San Paolo Albanese. La Edad y las condiciones sociales y culturales -pero no las económicas- son los factores que determinan la existencia de lo que podríamos llamar como habitus arbëreshë (Martínez García, 2017: 3). Sin embargo, el carácter reproductivo del habitus arbëreshë parece haber perdido fuerza entre las generaciones más jóvenes. Por lo que atañe a la lengua, entre los jóvenes de Civita, sin embargo, pocos declaran hablar a la perfección el arbëreshë. Si la lengua arbëreshë no ha desaparecido todavía en esta zona se debe con mucha probabilidad a su aislamiento geográfico y económico (Gambarara, 1994: 45). Algo que se hace evidente también en los datos que hemos recogido durante nuestro trabajo de campo: los pueblos en los que más se han mantenido las tradiciones -como los trajes tradicionales y el rito del matrimonio, conocido como «coronación» de los novios- y en los que se habla más el arbëreshë son los que están más aislados, es decir San Paolo y San Costantino. La fuerte endogamia, habitual hasta hace pocas décadas, ha contribuido a mantener el aislamiento $y$, por ende, la lengua y las tradiciones más que en otros sitios. Sin embargo, hoy se considera como totalmente normal el matrimonio mixto, entre un arbëreshë y un no arbëreshë. Como nos han confirmado también varios testigos, con los cuales hemos podido hablar, ya no existe en el imaginario colectivo arbëreshë un nosotros contrapuesto a los demás, es decir la idea de que haya que defender la identidad pura arbëreshë de las contaminaciones externas (Pavane- 
llo, 2010: VII). Mariano Pavanello nos recuerda (2010: X) que hoy «las sociedades contemporáneas no pueden tener un carácter étnico y monocultural». Los jóvenes arbëreshë, que hoy día estudian o trabajan lejos de sus pueblos, son libres de elegir sus pautas culturales de referencia, lo cual por ende puede problematizar «la autenticidad de las prácticas culturales» (Stocking, 2002: 30). En Civita y en Frascineto, unos pueblos un poco más grandes y con unas salidas de la autopista y por ende un menor nivel de aislamiento, la mayoría de los jóvenes parece no dominar la lengua arbëreshë. Lo mismo ocurre, según lo que nos ha confirmado la guía del museo de la cultura arbëreshë de San Paolo Albanese, en otros pueblos arbëreshë de la Basilicata, como Barile y Ginestra, que nosotros de todas formas no hemos tomado en consideración en la presente investigación. Además, hay que tener en cuenta que sólo en los últimos tiempos estos pueblos se han abierto al turismo, un turismo sobre todo de carácter nacional, aunque en tiempos más recientes han empezado a visitarlos también algunos turistas internacionales. Además del aislamiento, nos parece que la obstinación y el orgullo, como nos ha confirmado la responsable del Museo etnográfico de San Costantino, son características propias del pueblo arbëreshë que pueden explicar la persistencia del idioma y de ciertos rasgos culturales. Por otro lado, no hemos percibido la existencia de una ideologización de la lengua arbëreshë (Garrido, 2013), dado que sólo una reducida minoría parece usar esta lengua con fines políticos, como para conseguir diferenciarse de los pueblos limítrofes o de los demás italianos, que no hablan arbëreshë. Podemos afirmar que por lo general la minoría arbëreshë parece bien integrada y que sólo una reducida minoría declara haberse avergonzado en algunos momentos de su vida por su cultura.

El hecho de que el arbëreshë se hable sobre todo en casa, en familia o con amigos, demuestra que se percibe casi como una lengua menor y se relaciona con la idea de «un código sociolingüístico poco elaborado», si utilizamos la terminología de Basil Bernstein (1971). Sin embargo, el hecho de que el arbëreshë no sea una lengua utilizada sólo en los días de fiesta, como demuestran claramente los resultados de nuestra encuesta, pone en evidencia que estamos ante un idioma bien vivo, aunque amenazado por la asimilación y por la cultura global y cosmopolita de los más jóvenes, menos pegados a las tradiciones respecto a la de los más ancianos.

Sería interesante, en investigaciones futuras, tomar en consideración el papel de las políticas públicas en defensa de las minorías lingüísticas y las consecuencias que estas políticas han producido en relación con la defensa del arbëreshë como lengua minoritaria, en riesgo de desaparición (Ragni, 2007). 


\section{Bibliografía}

ALTIMARI, Francesco (1994). «Gli Arbëreshë: significato di una presenza storica, culturale e lingüística», en F. Altimari y L.M. Savoia, I dialetti italo-albanesi. Roma: Bulzoni.

ÁLVAREZ ÁLVAREZ, Carmen y SAN FABIÁN MAROTO, José Luís (2012). «La elección del estudio de caso en investigación educativa». Gazeta de Antropología, 28 (1): artículo 14.

AMATO, Stefano (2016). La Calabria arbëreshë. Frascineto tra medioevo e Neobizantinismo. Roma: Stamen.

ARTEMEL, Suheyla (1965) The idea of Turkey in the Elizabethan period and in the early seventeenth century with special reference to the drama. Durham theses. Durham, UK.: Durham University, accesible en http://etheses.dur.ac.uk/7961/ (Visitado 26/12/2017).

BARGERO, Mariano (2016). «Pensar la noción de tradición desde una perspectiva wittgensteiniana». RIS, 74 (1): 1-13.

BERNSTEIN, Basil ([1971] 2003). Class, codes and control, vol. 1. Londres: Routledge y Kegan Paul.

BERRUTO, Gaetano (2004). Prima lezione di sociolinguistica. Roma-Bari: Laterza.

BLOISE, Salvator (Comp. y Ed.) (2013). Ancestors of Salvatore Bloise and Rose Pippo. USA: Victorious People Publishing Company.

BRUNI, Pierfranco (2004). Arbëreshë: Cultura e civilità di un popolo. Roma: Instituto Poligráfico e Zecca dello Stato.

BULTMANN, Rudolf Karl (1948). «Neues Testament und Mythologie», en H-W. BARTSCH, (Ed.) Kerygma und Mythos. Hamburg-Bergstedt: Herbert Reich. Evangelischer Verlag G.m.b.H., 15-48.

CALLEJO, Javier (1998). «Sobre el uso conjunto de prácticas cualitativas y cuantitativas». RIS, 21: 101-126.

COLE, Jeffrey E. (Ed.) (2011). Ethnic groups of Europe. Santa Barbara CA.: ABCCLIO.

COZZETTO, Fausto (2013). «Introduzione alla parte prima», en Fulvio MAZZA (comp.). La Calabria albanese. Storia, cultura, economia. Soveria Monnelli: Rubbettino, 17-21.

DALENA, Pietro y DI MURO, Alessandro (2013). «Dalle origini al Medioevo», en F. Mazza (coord.), La Calabria albanese. Storia, cultura, economia. Soveria Mannelli: Rubbettino.

ELSIE, Robert (2010). Historical Dictionary of Albania. Lanham; Toronto: The Scarecrow Press, Inc.

ETHNOLOGUE (2016). "Albanian, Arbëreshe», (19th ed., 2016), en Ethnologue. Languages of the World, accesible en https://www.ethnologue.com/language/ aae, (visitado el 21/12/2017). 
FILIPPELLI, Giuseppe (2011). Tra le comunitá arbëreshë della media Calabria. Macerata: Edizioni Simple.

GAMBARARA, D. (1994). «Parlare albanese nell'Italia Unita», en Francesco Altimari y Leonardo M. Savoia (1994). I dialetti italo-albanesi. Roma: Bulzoni Editore.

GARRIDO, María Rosa (2013). «Un enfoque inclusivo y transnacional a las ideologías lingüísticas». Revista de Antropología Social, 22: 355-368.

GÓMEZ PELLÓN, Eloy (2012). «Las premisas epistemológicas y la antropología social». Gazeta de Antropología Social, 28 (1): artículo 10.

JURGENS, J. (2017). «Albanian Americans», en World Culture Encyclopedia, accesible en http://www.everyculture.com/multi/A-Br/Albanian-Americans. html (visitado el 20/12/2017).

MARINESCU, Constantin (1923). Alphonse V, roi d'Aragon et de Naples, et l'Albanie de Scanderbeg. Paris: Gamber.

MARTÍNEZ GARCÍA, José Saturnino (2017). «El habitus. Una revisión analítica». RIS, 75 (3): 1-14.

MIRAGLIA, Letizia (2000). «Gli Arbëreshë di Calabria fra tradizione e rinnovamento», Annali della Facoltá di Lettere e Filosofia, 43: 311-338.

MONTOBBIO, Manuel (2009). Arberia-Sefarad : las relaciones entre Skanderbeg y la Corona de Aragón y las experiencias paralelas de los Sefardíes y los Arberesh. Madrid: Agencia Española de Cooperación Internacional para el Desarrollo.

MORASSI, Luciana (1989). Ospitalità sanitaria in Udine. Tarcento (UD): Casamassima.

PAVANELLO, Mariano (2010). Fare antropologia. Metodi per la ricerca etnografica. Bologna: Zanichelli.

PIERONI, Andrea, et al. (2002). "Ethnopharmacy of the ethnic Albanians (Arbëreshë) of northern Basilicata, Italy», en Fitoterapia, 73: 217-241.

RAGNI, Tiziana (Dir.) (2007). Le minoranze linguistiche in Italia nella prospettiva dell'educazione plurilingue. La legge n. 482/1999 sulle minoranze linguistiche nel settore scolastico. Bilancio dei primi sei anni di attuazione. Firenze: Le Monnier.

RIZZO, Sergio y STELLA, Gian Antonio. (2010). «Il Risorgimento silenzioso dei nuovi albanesi». Il Corriere della Sera: 14 de agosto de 2010. www.corriere.it.

ROSTAGNOL, Susana (2011). «Trabajo de campo en entornos diversos. Reflexiones sobre las estrategias de conocimiento». Gazeta de Antropología, 27 (1): artículo 15.

SACCO, Viviana (2007). «La valoración de la idenidad cultural como base del desarrollo rural: el caso de la calabria Grecánica y el festival Paleariza». Revista Opera, 7:213-223, accesible en http://www.redalyc.org/articulo.oa?id=67500711 (Visitado el 27/12/2017). 
SALMINEN, Tapani (1999). UNESCO red Book on endangered languages: Europe, accesible en http://www.helsinki.fi/ tasalmin/europe_report.html (Visitado, 24/06/2018).

SÁNCHEZ-DAVID, Carlos E. (2008). «La muerte negra. 'El avance de la peste’», Revista Med, 16, no 1: 133-135.

SANMARTÍ ROSET, J. Monserrat (1995). Las políticas lingüísticas y la inserción de las lenguas minoritarias en el proceso de construcción de Europa. Tesis doctoral. Madrid. Universidad Complutense de Madrid, accesible en http://eprints.ucm. es/1869/1/T20799.pdf (Visitado el 27/12/2017).

SCHMITT, Oliver Jens (2009). Skanderbeg. Der neue Alexander auf dem Balkan. Regensburg: Verlag Friedrich Pustet.

SCUTARI, Pasquale (ed.) (2010). Gli Arbëreshë e la "Rilindja. Il contributo al Risorgimento degli intellettuali di San Costanino Albanese. Rende: Università della Calabria.

SERPE, Brunella (2012). L’identità negata: la minoría italo.albanese nel Mezzogiorno d'Italia. Roma: Carocci.

SERVANTIE, Alain (Ed.) (2003). El Imperio Ottomano en la Europa Renacentista. Lovaina: Leuven University Press.

STOCKING, George W. (2002). «Delimitando la antropología: reflexiones históricas acerca de las fronteras de una disciplina sin fronteras». Revista de Antropología Social, 11: 11-38.

TAGARELLI, Antonio (2004). Studio antropologico della comunità arbëreshë della provincia di Torino. Torino: Librare.

TYLOR, Edward Burnett (1920). Primitive Culture. (2 vols.). Londres: John Murray. UÑA JUÁREZ, Octavio y MARTÍN CABELLO, Antonio (2009). Introducción a la Sociología. Madrid: Universitas.

WITTGENSTEIN, Ludwig ([1953]1999). Philosophische Untersuchungen. Malden. Mass.: Blackwell Publishers. 
